\section{Effect of catanospermine, 1-deoxynojirimycin or 1-deoxymannojirimycin on biological and functional activities of Japanese encephalitis virus in porcine stable kidney cells}

\author{
Vaibhavi Jawahar Lad, Vikas R. Shende, \\ Ashok Kumar Gupta
}

National Institute of Virology (ICMR), Pune, Maharashtra, India

\begin{abstract}
In the present study, effect of catanospermine (CST), 1-deoxynojirimycin (DNJ) or 1deoxymannojirimycin (DMJ) was studied on porcine stable kidney (PS) cells infected with Japanese encephalitis virus (JEV). As both CST and DNJ are potent inhibitors of ER alpha-glucosidases 1 and II, while DMJ is an inhibitor of Golgi mannosidase which removes alpha $(1,2)$ Man residues from the $\mathrm{N}$-glycan precursor. Treatment of infected cells with CST $(200 \mathrm{uM} / \mathrm{mL})$, DNJ $(100 \mathrm{uM} / \mathrm{mL})$ or DMJ $(200 \mathrm{uM} / \mathrm{mL})$ did not produce much effect on viral gpE epitope presentation within the cells as well as on the cell surface as detected in the immunofluorescence employing monoclonal (MAbs) and polyclonal (PAbs) antibodies. As well the treated (infected) cells showed only a marginal decrease in infectious virus yield along with a slight decrease in haemagglutination activity of the virus that was recorded in comparison to the untreated infected (control) cells and the cells infected with Dengue virus. Immuno-blotting of the separated proteins from infected lysed cells and probed with anti-gpE MAbs also revealed a band corresponding to JEV gpE (MW $53 \mathrm{kDa}$ ) both with inhibitor treated and the untreated cells; the reactivity with the former however, was somewhat less intense and prominent in comparison to latter (control untreated) indicating some effect on JEV. The present results indicate that these inhibitors by in large, do not affect maturation and the release of infective JE virions in PS cells.
\end{abstract}

\section{Introduction}

Japanese encephalitis virus (JEV) is one of the most dreaded mosquito-borne flaviviruses (genus: Flavivirus, family: Flaviviridae) that causes frequent epidemics of acute encephalitis throughout South-east Asia and Western
Pacific regions. ${ }^{1-3}$ The disease has also emerged in the non-Asian region such as Northern Australia as reported in recent past. ${ }^{4}$ Initially both adults and children are affected, while lately it is mostly children who suffer from JE in affected areas during subsequent attacks. The mortality as high as $40 \%$ was recorded in some of the JE affected areas. Moreover, many survivors face some neurological problems and complications. ${ }^{2,3}$ Even though there are vaccines available, no any specific antiviral therapeutics are yet available for the treatment. ${ }^{5,6}$

JEV as like many other flaviviruses are known to replicate exclusively in the cytoplasm and mature on the intracellular membranes of infected cells. ${ }^{7,8}$ Employing the intrinsic secreting pathway of infected cells, flaviviruses bud from the membranes of endoplasmic reticulum (ER) and the Golgi apparatus to release mature virions. ${ }^{9}$ It has earlier been shown with some enveloped viruses viz., human immunodeficiency virus, hepatitis B and $C$ viruses, dengue viruses that are greatly affected in cells when alpha-glucosidase mediated $\mathrm{N}$-linked oligosaccharide trimming is inhibited. ${ }^{10-16}$ The initial steps of $\mathrm{N}$-linked oligosaccharide processing on the glycoprotein in the ER involve the sequential trimming of the glucose residues on oligosaccharide precursor Glc3Man9GlcNAc2 after it is transferred from the dolichol diphosphate to the growing polypeptide backbone. ${ }^{17}$ ER alpha-glucosidases I and II are involved initially in the trimming pathway; alpha-glucosidase I removes the terminal alpha $(1,2)$-linked glucose from Glc3Man9GlcNAc2, whereas alpha-glucosidase II removes the second and possibly the third alpha(1,3)-linked glucose residues. ${ }^{18}$ As castanospermine (CST) and deoxynojirimycin (DNJ) are well-known ER alpha-glucosidase inhibitors both inhibiting the early stages of glycoprotein processing whereas 1-deoxymannojirimycin (DMJ) is an inhibitor of Golgi mannosidase which removes alpha $(1,2)$ Man residues from the $\mathrm{N}$-glycan precursor. In the present study, we therefore investigated whether these inhibitors are effective in inhibiting JEV production in a model using PS cells.

\section{Materials and Methods}

\section{Virus and cells}

The details of JEV and PS cells used during the study are given elsewhere. ${ }^{19,20}$ In brief, JEV strain 733913 , originally isolated from a fatal case of JE was adapted to PS cells grown in Earle's based minimum essential medium (MEM, Gibco, Invitrogen Corp., Carlsbad, CA, USA) supplemented with $10 \%$ of goat serum.
Correspondence: Ashok Kumar Gupta, Centre for Biotechnology, Pravara Institute of Medical Sciences, Loni - 413736, Maharashtra, India. Tel. +91.9960071291 - Fax: +91.2422273413 E-mail: drashok.gpt@gmail.com

Key words: Japanese encephalitis virus catanospermine, 1-deoxynojirimycin, 1-deoxymannojirimycin, PS cells.

Acknowledgments: authors are thankful to Director, National Institute of Virology, Pune for the facilities and Mrs. S. A. Sarthi for providing monoclonal antibodies.

Contributions: VJL, her work was a part of her Ph. D. project; VRS, helped in carrying out some of the experimental work and in preparation of MS; $\mathrm{AKG}$, is the research guide and supervisor.

Conflict of interests: the authors declare no potential conflict of interests.

Received for publication: 21 November 2011. Revision received: 27 June 2012.

Accepted for publication: 29 August 2012.

This work is licensed under a Creative Commons Attribution NonCommercial 3.0 License (CC BYNC 3.0).

(C) Copyright V.J. Lad et al., 2013

Licensee PAGEPress, Italy

Microbiology Research 2013; 4:e3

doi:10.4081/mr.2013.e3

Also strain P23085 of DENV-2 adapted to PS cells was included. The virus passaging in PS cells was carried out in MEM supplemented with $2 \%$ goat serum and the virus stocks were stored at $-70^{\circ} \mathrm{C}$.

\section{Monoclonal and polyclonal anti- bodies}

Monoclonal antibodies (MAbs) were raised earlier in our laboratory against JEV gpE and were grouped as HAI-positive, HAI-negative virus-specific, HAI-positive, HAI-negative flavivirus cross-reactive and HAI-negative autoreactive MAbs depending on their reactivity with JEV, West Nile and Dengue (DEN) viruses. ${ }^{21,22}$ The respective hybrid cells were maintained in the Dulbecco's based MEM supplemented with $10 \%$ fetal calf serum (both from Gibco) and were inoculated intra-peritoneally into pristane-primed $\mathrm{BALB} / \mathrm{c}$ mice, ascitic fluids (AFs) were collected by standard methods. Control AF was also obtained by inoculating SP2/0 cells or a MAb prepared against Chikungunya virus (CHIKV-an Alphavirus, the family: Togaviridiae) which did not cross-react with JEV, served as negative control. Polyclonal antibodies (PAbs) to JEV and a control AF were raised in Swiss mice by immunization with 
JEV or control (uninfected) antigen respectively, followed by ascites production employing Ehrlich's tumor cells by standard procedures.

\section{Japanese encephalitis virus and} Dengue virus- 2 infections and catanospermine, 1-deoxynojirimycin or 1-deoxymannojirimycin treatment of PS cells

Confluent PS monolayers grown in 2.5" petri dishes and on coverslips in Leighton tubes were infected with JEV as mentioned elsewhere..$^{19,20}$ After virus adsorption at $37^{\circ} \mathrm{C}$ for $1 \mathrm{hr}$, the virus inoculum was removed and MEM supplemented with $2 \%$ goat serum and CST $(200 \mathrm{uM} / \mathrm{mL})$, DNJ $(100 \mathrm{uM} / \mathrm{mL})$ or DMJ (200 uM/mL) (all three from Sigma-Aldrich Corp., St. Louis, MO, USA) was added. The cells grown on medium but without CST, DNJ or DMJ served as controls. As these inhibitors have shown to inhibit DEN virus replication, therefore cells infected with DENV 2, both treated and untreated cells were included in the experiments. The concentrations of CST, DNJ or DMJ have been worked out prior to the experimental work and at the given concentrations no any morphological changes indicative of cell toxicity were observed. The cells were incubated for various times at $37^{\circ} \mathrm{C}$ prior to assaying the infectious virus and for antigenicity by IF. Also tunicamycin (Tm-3 ug/mL) (Sigma) treated cells were additionally included as positive controls. ${ }^{19}$

\section{Immunofluorescence studies}

Coverslips with virus-infected cell monolayers either treated or untreated with CST, DNJ, DMJ or Tm were fixed at $24 \mathrm{~h}$ and $48 \mathrm{~h}$ postinfection (p.i.) in chilled acetone $\left(-20^{\circ} \mathrm{C}\right)$ for 20 min, probed with anti-gpE JEV MAbs or PAbs diluted 1:100 and stained with a goat anti-mouse immunoglobulin fluorescein isothiocyanate (GAM Ig-FITC) conjugate (Sigma). ${ }^{23}$ The cells were also probed for surface immunofluorescence (IF) at $36 \mathrm{~h}$ p.i. by treating the unfixed cells with different MAbs or PAbs diluted 1:100 in MEM containing sodium azide as mentioned earlier. ${ }^{24}$ Subsequently, the antibody-treated cells were fixed in chilled acetone $\left(-20^{\circ} \mathrm{C}\right)$ for $20 \mathrm{~min}$ and stained with a GAM Ig-FITC conjugate as above.

\section{Assaying of infectious virus}

Tissue culture supernates (TCFs) and cell lysates collected from the treated cells and the untreated (control) cells at $48 \mathrm{~h}$ p.i. were assayed for the infectious virus in vitro (by plaque titration in PS cells using 24-well plate) as described earlier. ${ }^{19,20}$ The results were expressed as $\log$ PFU/mL. Further the TCFs were titrated for the infectious virus yield by intracerebral (i.c.) inoculation in 2-3 days old infant Swiss mice as detailed elsewhere. ${ }^{19}$

\section{Hemagglutination assay}

The effect of CST, DNJ, DMJ or Tm on HA activity of the virus was additionally studied by assaying HA titres of the TCFs and cell lysates collected from both the treated and the untreated virus-infected cells employing goose erythrocytes as described earlier. ${ }^{19,20}$

\section{Western blotting}

Treated and untreated cells were lysed with Laemmmli buffer were electrophoresed using $10 \%$ SDS-polyacrylamide (SDS-PAGE) as described by Laemmli. ${ }^{25}$ This was followed by transfer onto nitrocellulose membrane (Schleicher and Schuell, West Germany). The membranes were blocked and probed with JEV anti-gpE MAbs and detected with an alkaline phosphatase-conjugated goat anti-mouse antibody (GAM Ig-AP, Bio Rad).

\section{Results}

Incubation of JEV-infected cells in presence of CST, DNJ or DMJ added immediately after virus adsorption resulted in reduction by about 0.6-1.0 $\log$ PFU/mL both in the intracellular (i.e. cell lysates) and extracellular (i.e. TCFs) infectious virus yield at $48 \mathrm{~h}$ p.i. (Figure 1). Similarly, HA activity of the virus was only marginally affected as the treated cells showed a little lower HA titres (a titre of 1:48 to 1:64) in comparison to the untreated cells (a titre of 1:96). In contrast, DENV-2 infected cells showed a drastic reduction (yielding about 1.0 $\log \mathrm{PFU} / \mathrm{mL}$ of the virus) in presence of the inhibitors in comparison to the untreated controls yielding approx. $7.0 \log$ PFU/mL of the virus. Also Tm treated cells showed marked reduction in the intracellular and extra-cellu- lar infectious virus yield (untreated controls yielding 7.0-8.0 $\log \mathrm{PFU} / \mathrm{mL}$ of the virus as against 2.0-3.0 $\log$ PFU/mL with the Tm treated cells). Similarly, the i.c. titration of the TCFs from $\mathrm{Tm}$ treated infected cells yielded a virus titre of $2.9 \log \mathrm{LD}_{50} / 0.02 \mathrm{~mL}$ as against $7.2 \log$ $\mathrm{LD}_{50} / 0.02 \mathrm{~mL}$ of the virus obtained with untreated controls.

The results thus indicated that these glucosidase inhibitors did not affect much the JEV production in comparison to DENV-2 grown under similar conditions. Although there were no direct indications of the inhibitors absorption, the DENV-2 inhibition in present study suggested that the inhibitors were invariably absorbed to PS cells. Further, the treatment of cells with the inhibitors produced a dose dependent response as observed with DENV-2 (data not shown). Also more than 95\% of the cells incubated for $24 \mathrm{~h}$ with CST $(200 \mathrm{uM} / \mathrm{mL})$, DNJ (100 uM/mL) or DMJ (200 uM/mL) still excluded trypan blue and no obvious morphological changes such as cell rounding, shrinking or swelling and detachment of cells from solid surfaces were observed between treated and untreated cells.

The intracellular presentation of the epitopes on JEV gpE appeared to be unaffected by the CST, DNJ or DMJ treatment of infected cells which showed characteristic apple- green IF at $24 \mathrm{~h}$ and $48 \mathrm{~h}$ p.i. with the MAbs and PAbs to JEV. Also the treated cells produced IF of similar magnitude on the cell surface at $36 \mathrm{~h}$ p.i., whereas no IF (both cytoplasmic and surface IF) was detected at all with the Tm cells. No IF with SP2/0 or CHIKV MAb and control AF was seen with treated or untreated infected cells by either method. Immuno-blotting of the separated proteins probed with anti-gpE MAbs also revealed a band corresponding to JEV gpE (MW 53kDa) both with inhibitor treated (CST, DNJ or DMJ) and the untreated cells; the reactivity with the former cells was somewhat less intense and prominent in comparison to latter

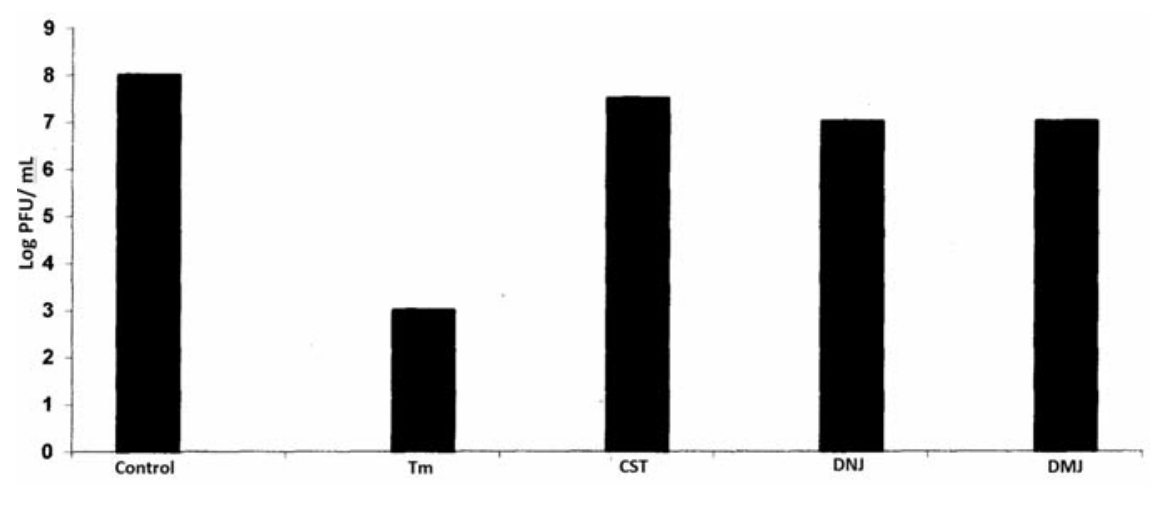

Figure 1. Virus infectivity in tissue culture supernates collected from the untreated and the treated cells at $48 \mathrm{~h}$ p.i. 
(control untreated) indicating some effect on JEV (Figure 2). In contrast, no band corresponding to JEV gpE (MW 53kDa) was however, revealed with Tm treated cells.

\section{Discussion}

The entry of flavivirus in host cell usually occurs via receptor mediated endocytosis and heparan sulfate present on mammalian cells that commonly act as receptors in the virus host-cell interactions. ${ }^{26-28}$ Following endocytosis, acidic $\mathrm{pH}$ of the endosome causes conformational changes in $\mathrm{E}$ protein exposing the hydrophobic domain required for membrane fusion that releases nucleocapsid into cytoplasm of the infected cell. ${ }^{29,30}$ Most of the gps undergo folding which attain native conformation being chaperoned through the ER resident molecular chaperons i.e., membrane-bound calnexin and its soluble homologue calreticulin. ${ }^{31-33}$ As Tm is known to block the attainment of native structure by $\mathrm{E}$ protein that in turn, affects its expression on the surface of infected PS cells. ${ }^{19,34}$ On other hand, in Tm absence co-translationally added N-linked gly-

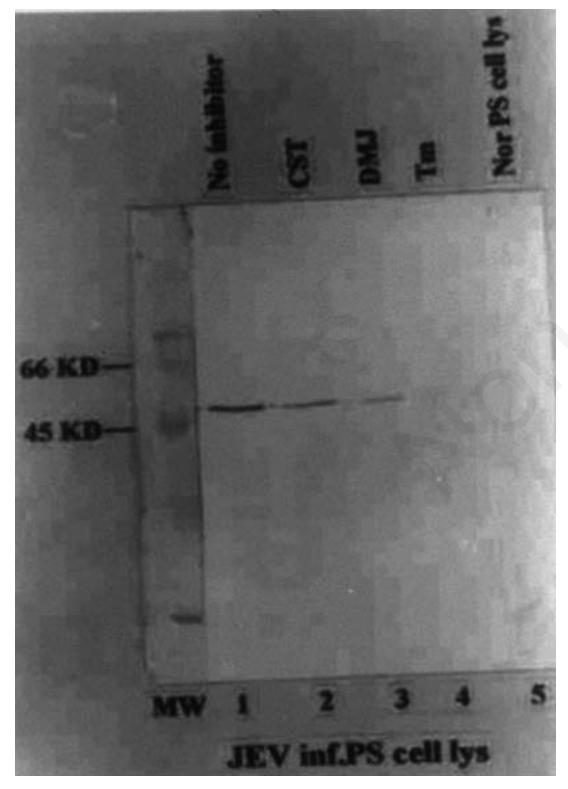

Figure 2. Reactivity of cell lysates of the untreated and treated Japanese encephalitis virus infected cells with anti-gpE MAb in Western blot showing single band at around $53 \mathrm{kDa}$ in lanes Nos. 1, 2 and 3. MW, molecular markers; 1, control (untreated infected) cells; 2, CST treated cells; 3, DMJ treated cells; 4, Tm treated cells; 5, uninfected PS cells; CST, catanospermine; DMJ, 1-deoxymannojirimycin; Tm, tunicamycin. can precursor (glyococalices) on newly synthesized protein is processed initially by removing terminal glucose residues by the ER alpha-glucosidases 1 and II. Both CST and DNJ are well known inhibitors of ER alpha-glucosidases 1 and II. ${ }^{14,35,36}$ and the prevention of Glc residues trimming by ER alpha-glucosidases 1 and II inhibits the activity of ER resident molecular chaperons which specifically binds to monoglucosylated gps till the proteins attain native conformation. ${ }^{32,33,36}$ After removal of three glucose residues in the ER, one mannose (alphal, 2) is additionally cleaved (cleaved from the Man alpha 1, 6 branch) by ER mannosidase as a result high mannose type glycans $\left(\mathrm{GlcNAc}_{2} \mathrm{Man}_{8}\right)$ are formed. In order to further processing, the gps are transported through vesicles to the Golgi alpha $(1,2)$ mannosidase which specifically cleaves alpha 1,2 mannose residues and convert the glycan to $\mathrm{GlcNAc}_{2} \mathrm{Man}_{5}$ type. In contrast, DMJ is the inhibitor of Golgi alpha $(1,2)$ mannosidase 1 that prevents the formation of hybrid/complex type of oligossaharides; thus the glycans in its presence are rather of high mannose type $\left(\mathrm{GlcNAc}_{2} \mathrm{Man}_{8}\right) .{ }^{36,37}$

\section{Conclusions}

The present results indicate that glucosylated or high mannosylated gpE of JEV has no effect on the attainment of proper gpE conformation as evident by the reactivity of CST, DNJ or DMJ treated cells with the MAbs or PAbs in IF. Further, such a treatment of the cells has by in large, did not much affect the virus assembly as indicated by the infectious virus contents retaining biological (HA) activity of the virus. In studies by others, the cell type has however been shown to affect the susceptibility of vesicular stomatitis virus to some of glucosidases inhibitors which has been attributed to a Golgi apparatus-resident endomannosidase ${ }^{38}$ Although there were no direct indications of these inhibitors absorption, the inhibition of DENV-2 grown under similar conditions in present study suggested that the inhibitors were invariably absorbed to PS cells. Also some variations in the susceptibility to glucosidases amongst flaviviruses may be related to a differential requirement for associating with the chaperones calnexin and calreticulin. ${ }^{15}$ Therefore, at least one of the glycans on the prM or E of DENV, but not in case of WNV or JEV as indicative from the present results that may essentially be required for calnexin-mediated protein folding, oligomerization, and virion assembly. ${ }^{39}$ There are however some contra-indications to this as well as DENV structural proteins have also been reported not to be associated with chaperones in infected cells. ${ }^{40}$
Earlier, it was reported that both DENV-2 and JEV were inhibited by N-nonyl(NN)-DNJ, ${ }^{41}$ indicating some role of ER glucosidases in $\mathrm{E}$ protein processing and thus of molecular chaperons in proper folding/conformation of the viral gps. Further studies in this aspect however, has indicated that long alkyl chain present in iminosugar of N-nonyl(NN)-DNJ itself produced anti-viral effect by interfering in glycolipid synthesis rather than inhibition of ER glucosidases. $^{42}$ Also a differential effect of DNJ and NN-DNJ on Kunjin virus (KUNV) has been reported as the treatment of KUNV-infected cells with the latter i.e., NN-DNJ resulted in reduced infectious virus yield but none with the former treatment. ${ }^{43}$ Furthermore, the flaviviruses which are strongly retained in the ER would probably be more susceptible as they do not appreciably traffic through the Golgi network and encounter the resident escape mannosidase that allows carbohydrate processing and proper viral protein folding. ${ }^{15}$ Alternatively, amongst flaviviruses even a difference in transit time through the Golgi network could affect exposure to escape mannosidases that however, remains to be determined. ${ }^{20}$

\section{References}

1. Monath TP, Heinz FX. Flaviviruses. In: Fields BN, Koipe DM, Howley PM, eds. Field's Virology. 3rd ed. Philadelphia: Lippincott- Raven; 1996. pp. 961-1034.

2. Solomon T, Ni H, Beasley DW, et al. Origin and evolution of Japanese encephalitis virus in Southeast Asia. J Virol 2003;77: 3091-8.

3. Vaughn DW, Hoke CH. The epidemiology of Japanese encephalitis: prospects for prevention. Epidemiol Rev 1992;14:197221.

4. Hanna JN, Ritchie SA, Philips DA, et al. Japanese encephalitis in North Queensland, Australia, 1998. Med J Aust 1999;170:533-66.

5. Gupta AK, Koshy AA, Lad VJ. Enhanced protection of mice against Japanese encephalitis virus infection by combinations of monoclonal antibodies to glycoprotein E. Acta Virol 2011;55:165-8.

6. Gupta AK, Koshy AA, Lad VJ. Protection of mice against Japanese encephalitis virus group II strains infection by combinations of monoclonal antibodies to different antigenic domains on glycoprotein Microbiol Res 201012;3:e17.

7. Brinton MA. Replication of flaviviruses. In: Schlesinger S, Schlesinger MJ, eds. The togaviridae and flaviviridae. New YorkLondon: Plenum Press; 1986. pp. 327-74.

8. White D0, Fenner F, eds. Togaviruses and flaviviruses. In: Medical Virology. Part II. 
3rd ed. New York-London: Academic Press Inc.; 1986. pp. 479-508.

9. Rice CM, ed. Flaviviridae: the viruses and their replication. In: Fields virology. 3rd ed. Philadelphia: Lippincott-Raven Publishers; 1996. pp. 931-59.

10. Block, TM, Lu X, Mehta A, et al. Treatment of chronic hepadnavirus infection in a woodchuck animal model with an inhibitor of protein folding and trafficking. Nat Med 1998;4:610-4.

11. Block TM, Lu X, Platt FM, et al. Secretion of human hepatitis B virus is inhibited by the imino sugar N-butyldeoxynojirimycin. Proc Natl Acad Sci USA 1994;91:2235-9.

12. Fischer PB, Collin M, Karlsson GB, et al. The a-glucosidase inhibitor Nbutyldeoxynojirimycin inhibits human immunodeficiency virus entry at the level of post-CD4 binding. J Virol 1995;69:57917.

13. Lu X, Mehta A, Dadmarz M, et al. Aberrant trafficking of hepatitis B virus glycoproteins in cells in which $\mathrm{N}$-glycan processing is inhibited. Proc Natl Acad Sci USA 1997;94:2380-5.

14. Mehta A, Zitzmann N, Rudd PM, et al. Alpha glucosidase inhibitors as potential broad based anti-viral agents. FEBS Lett 1998;430:17-22.

15. Whitby K, Pierson TC, Geiss B, et al. Castanospermine, a potent inhibitor of dengue virus infection in vitro and in vivo. J Virol 2005;79:8698-706.

16. Qu X, Pan X, Weidner J, et al. Inhibitors of endoplasmic reticulum î̀-glucosidases potently suppress hepatitis $\mathrm{C}$ virus virion assembly and release. Antimicrob Agents Chemother 2011;55:1036-44.

17. Trombetta ES, Helenius A. Lectins as chaperones in glycoprotein folding. Curr Opin Struct Biol 1998;8:587-92.

18. Hebert DN, Foellmer B, Helenius A. Glucose trimming and reglucosylation determine glycoprotein association with calnexin in the endoplasmic reticulum. Cell 1995;81:425-33.

19. Lad VJ, Shende VR, Gupta AK, et al. Effect of tunicamycin on expression of epitopes on Japanese encephalitis virus glycoprotein E in porcine kidney cells. Acta Virol 2000;44:359-64.

20. Lad VJ, Gupta AK. Effect of brefelidin A and monensin on Japanese encephalitis virus maturation and virus release from cells.
Microbiol Res 2011;2:e9.

21. Kedarnath N, Dayaraj C, Sathe PS, et al. Monoclonal antibodies against Japanese encephalitis virus. Indian $\mathrm{J}$ Med Res 1986;84:125-33.

22. Cecilia D, Gadkari D, Kedarnath N, Ghosh SN. Epitope mapping of Japanese encephalitis virus envelope protein using monoclonal antibodies against an Indian strain. J Gen Virol 1988;69:2741-7.

23. Gupta AK, Gore MM, Lad VJ, Ghosh SN. Nuclear immunofluorescence in porcine kidney cells infected with Japanese encephalitis virus. Acta Virol 1991;35:2826.

24. Gupta AK, Lad VJ, Ghosh SN. Detection of viral antigens on the surface of the cells infected with Japanese encephalitis virus by modified immuno-fluorescent technique. Acta Virol 1993;37:93-6.

25. Laemmmli UK. Cleavage of structural proteins during the assembly of the head of bacteriophage T4. Nature 1970;227:680-5.

26. Rice CM, Strauss JH. Production of flavivirus polypeptides by proteolytic processing. Semin Virol 1990;1:357-67.

27. Chen Y, Maguirre T, Hileman RE, et al. Dengue virus infectivity depends on envelope protein binding to target cell heparin sulfate. Nat Med 1997;3:866-71.

28. Lee E, Lobigs M. Substitutions at the putative receptor-binding site of an encephalitic flavivirus after virulence and host cell trophism and reveal a role for glycosuminoglycans in entry. J Virol 2000;74: 8867-75.

29. Ishak R, Tovey DG, Howard CR. Morphogenesis of yellow fever virus 17D in infected cell cultures. J Gen Virol 1988; 69:325-35.

30. Guirakhoo F, Heinz FX, Kunz C. Epitope model of tick borne encephalitis virus envelope glycoprotein E analysis of structural properties role of carbohydrate side chain and conformational changes occurring at acidic pH. Virology 1989;169:90-9.

31. Ou WJ, Cameron PH, Thomas DY, Bergman JJ. Association of folding intermediates of glycoproteins with calnexin during protein maturation. Nature 1993; 364:771-6.

32. Hammond C, Braakman I, Helenius A. Role of N-linked oligosaccharide recognition, glucose trimming and calnexin in glycoprotein folding and quality control. Proc
Nat Acad Sci USA 1994;91:913-7.

33. Rodan AR, Simons JF, Trombetta ES, Helenius A. N-linked oligosaccharides are necessary and sufficient for association of glycosylated forms of bovine RNAse with calnexin and calreticulin. EMBO J 1996;15:6921-30.

34. Mason PW. Maturation of Japanese encephalitis virus glycoproteins produced by infected mammalian and mosquito cells. Virology 1989;169:354-64.

35. Saunier B, Kilker RD Jr, Tkacz JS, et al. Inhibition of N-linked complex oligosaccharide formation by 1-deoxynojirimycin, an inhibitor of processing glucosidases. J Biol Chem 1982;257:14135-61.

36. Elbein AD. Inhibitors of the biosynthesis and processing of $\mathrm{N}$-linked oligosaccharide chains. Annu Rev Biochem 1987; 56:497-534.

37. Fuhrmann U, Bause E, Ploegh $H$. Inhibitors of oligosaccharide processing. Biochem Biophys Acta 1985;825:95-110.

38. Karaivanova VK, Luan P, Spiro RG. Processing of viral envelope glycoprotein by the endomannosidase pathway: evaluation of host cell specificity. Glycobiol 1998;8:725-30.

39. Wu SF, Lee CJ, Liao CL, et al. Antiviral effects of an iminosugar derivative on flavivirus infections. J Virol 2002;76:3596604.

40. Courageot MP, Frenkiel MP, Dos Santos $\mathrm{CD}$, et al. Alpha-glucosidases inhibitors reduce dengue virus production by affecting initial steps of virion morphogenesis in the endoplasmic reticulum. J Virol 2000; 74:564-72.

41. Block TM, Jordan R. Iminosugar as possible broad based spectrum anti hepatitis: the glucovirs and alkovirs. Antivir Chem Chemother 2001;12:317-325.

42. Meilor A, Nolan J, Pickering L, et al. Preparation, biochemical characterization and biological properties of radio-labelled $\mathrm{N}$-alkylated deoxynorijimycins. Biochem J 2002;336:225-33.

43. Mackenzie JM, Westaway EG. Assembly and maturation of the flavivirus Kunjin Virus appear to occur in the rough endoplasmic reticulum and along the secretory pathway, respectively. J Virol 2001;75: 10787-99. 